\title{
Use of Solid Carbon Residue of Tire Pyrolysis as an Adsorbent for Organic Substances Removal from Water
}

\author{
Yevgenia Makarevich ${ }^{1, *}$, Andrey Papin ${ }^{1}$, and Eugen Domru ${ }^{2}$ \\ ${ }^{1}$ T.F. Gorbachev Kuzbass State Technical University, 650000, Kemerovo, Russian Federation \\ ${ }^{2}$ University of Petrosani, Faculty of Mining, 33200620 Universitasii str., Petrosani, Romania
}

\begin{abstract}
The study on preparation of sorbents based on carbon residue of tire pyrolysis is presented in the article. As a part of the study, carbon residue was refined to improve its processing characteristics. It is found that refining resulted in twofold total pore volume increase. Also, the iodine adsorption value depends on the time of reaction. Adsorption capacity increases as the time of interaction with iodine solution increases. Refined $0,2 \mathrm{~mm}$ size grade carbon black has the best adsorption value. When an aqueous solution of $1 \mathrm{~g} / \mathrm{dm}^{3}$ phenol was passed through the filter, the purification efficiency was about $35 \%$; when phenol concentration was $0,1 \mathrm{~g} / \mathrm{dm}^{3}$, purification efficiency amounted to about $85 \%$. The filter being re-used; the absorption capacity is reduced to $50 \%$. The absorption capacity decreases due to the sorbing micro-pore bridging. Phosphoric acid activation of spent adsorbent provides for the restoration of its sorption properties and allows its re-use.
\end{abstract}

\section{Introduction}

The solid carbon-containing residue of tire pyrolysis of the company LLC "KEK+" (Kaltan, Kemerovo region, Russia) was taken as the object of study. The solid residue has a toxic smell, which limits the possibilities of its use in various fields. The carried out element analysis showed that the solid residue of pyrolysis contains about $80 \mathrm{wt} . \%$ of C, 1.5 wt. $\%$ of $\mathrm{H}$.

\section{Materials and Methods}

Technical analysis of the original carbon residue was performed. As a result of data analysis, it was established that the carbon residue has high values of ash content (up to 20 wt. \%) and the yield of volatile substances (up to 12 wt. \%).

In the course of the work, studies were carried out on refining the solid carboncontaining residue by magnetic separation, gravity concentration, and thermal processing.

Thermal processing of solid residue of pyrolysis turns it into high-quality raw materials for obtaining smokeless fuels and sorbents. When the product is refined by thermal

${ }^{*}$ Corresponding author: pav.httt@,kuzstu.ru 
processing, its quality characteristics are improved, the characteristic smell disappears, pores are cleaned and cylindrical macro-holes become visible with the naked eye. This opens up prospects for using the produced refined carbon residue as an adsorbent.

Element analysis showed that the refined carbon residue contains $86 \mathrm{wt}$ \% of C, about 1.0 wt. $\%$ of $\mathrm{H}$.

The structure of the molecules of the solid carbon residue was also studied before (Fig. 1a) and after refining (Fig. 1b) using infrared spectroscopy. It was found that during thermal refinement, the breaking of multiple $\mathrm{C}-\mathrm{C}, \mathrm{C}-\mathrm{O}$ bonds and the splitting of organic polysulfide bonds occur.
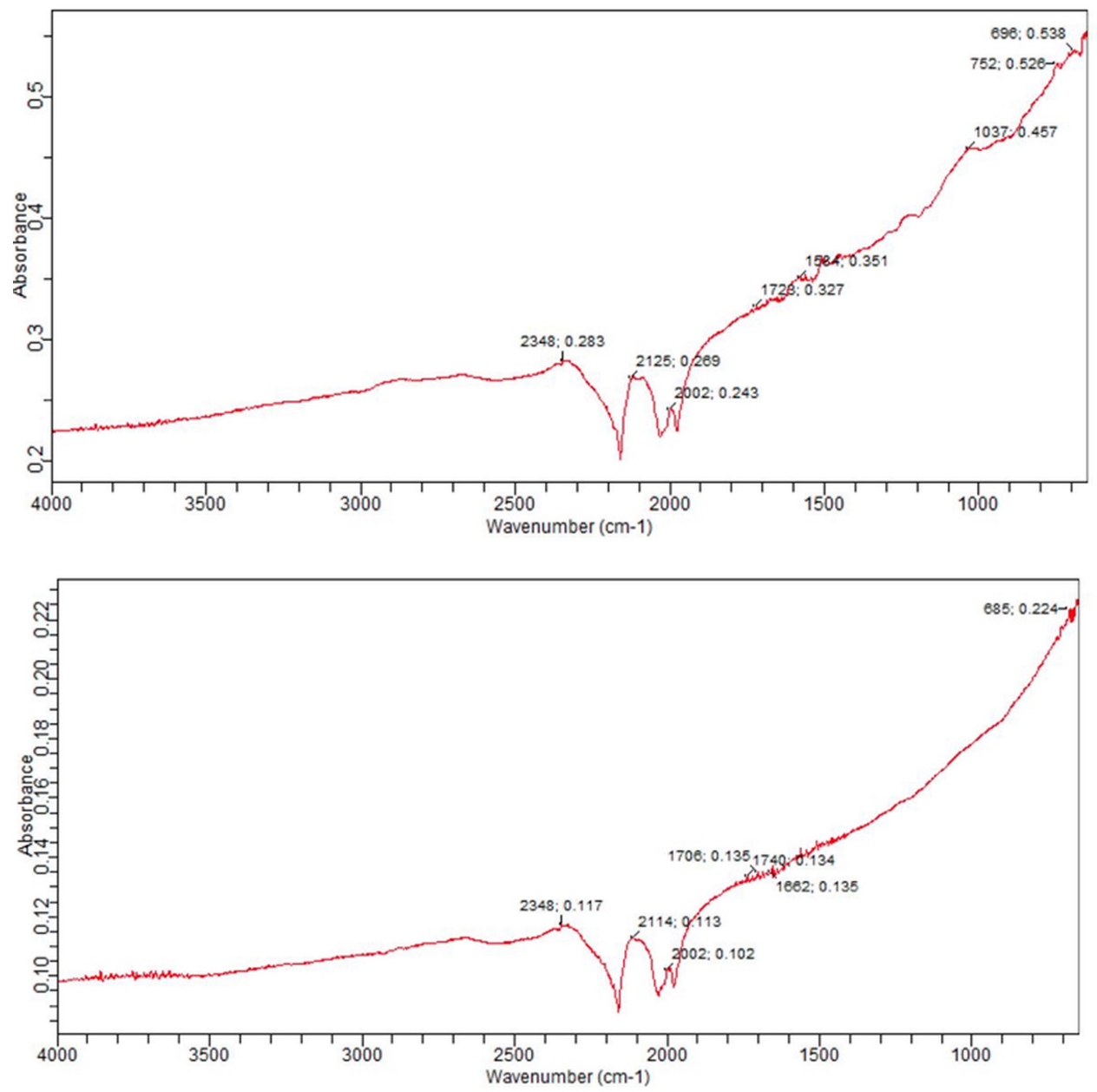

Fig.1. IR spectra of solid carbon residue of tire pyrolysis: a - IR spectrum of solid carbon residue before refining, $b$ - IR spectrum of the solid carbon residue of tire pyrolysis after refining.

In order to study the possible use of a carbon-containing solid residue of tire pyrolysis as an adsorbent, the total porosity, the specific surface area of methylene blue was determined, the temporal dependence of iodine adsorption value was investigated. 


\section{Results and Discussion}

From the results of determining the total pore volume of the carbon-containing residue of tire pyrolysis, it follows that during refining the pore volume increases by 2 times. After refining pores are clearly visible to the naked eye.

The $70-75 \mathrm{~m}^{2} / \mathrm{g}$ methylene blue specific surface area of the refined solid residue was determined.

The iodine adsorption capacity of the solid carbon residue was determined. Based on the data obtained, it can be concluded that the iodine adsorption capacity depends on the size of the adsorbent particles (solid carbon residue), on the time of the reaction. The smaller are the particles of the adsorbent and the longer is the time of interaction with the iodine solution, the higher is the adsorption value.

Table 1. The dependence of iodine adsorption value of a sorbent on the time of reaction.

\begin{tabular}{|c|c|c|c|}
\hline \multirow[t]{2}{*}{ Sample } & \multicolumn{3}{|c|}{$\begin{array}{l}\text { Iodine adsorption value of a sorbent on the time of } \\
\text { reaction, } \%\end{array}$} \\
\hline & $15 \mathrm{~min}$ & $20 \mathrm{~min}$ & 30 min \\
\hline $\begin{array}{l}\text { Refined carbon black, } \\
0.2 \mathrm{~mm} \text { size grade }\end{array}$ & 23,98 & 32,28 & 40,01 \\
\hline $\begin{array}{l}\text { Refined carbon black, } \\
1.5-1 \mathrm{~mm} \text { size grade }\end{array}$ & 13,13 & 15,20 & 16,17 \\
\hline $\begin{array}{l}\text { Solid residue of tire } \\
\text { pyrolysis, } \\
0.2 \mathrm{~mm} \text { size grade }\end{array}$ & 22,78 & 27,78 & 40,32 \\
\hline
\end{tabular}

Sewage is often contaminated with phenols. In order to avoid phenols in technical and drinking water, the formulation of the problem of complete phenol removal from water is extremely relevant at the moment. Its solution is carried out by the development of optimal process flowcharts and the search for new sorbents that can significantly reduce its content in water.

Therefore, we investigated the possibility of using a refined solid residue of tire pyrolysis for phenol removal from water. Sorption water purification was performed using the laboratory-scale plant. A refined 0,5-2 $\mathrm{mm}$ particle size solid carbon residue of tire pyrolysis was used as an adsorbent.

When an aqueous solution of $1 \mathrm{~g} / \mathrm{dm}^{3}$ phenol was passed through the filter, the purification efficiency was about $35 \%$. When the filter was re-used, the absorption capacity decreased to $15 \%$.

An aqueous solution of $0,1 \mathrm{~g} / \mathrm{dm}^{3}$ phenol being passed through the filter for the first time; the purification efficiency was $80-85 \%$. When the filter was re-used, the absorption capacity decreased to $60-65 \%$, with the third use - to $45-50 \%$.

The decrease in the absorption capacity occurs due to sorbing micro-pores bridging.

For the restoration of the spent adsorbent, the same process operations were used as in its production. It was found that after restoration, the adsorption value of the refined solid residue of pyrolysis with respect to phenol decreases. When an aqueous solution of 0,1 $\mathrm{g} / \mathrm{dm}^{3}$ phenol was passed through the filter, the purification efficiency was about $35-40 \%$. When the filter was re-used, the absorption capacity decreased to $20-22 \%$, with the third use - to $5-7 \%$. Thus, the chemical activation of the adsorbent is required to restore the adsorption properties. 


\section{Conclusion}

Phosphoric acid activation of the spent adsorbent provides the restoration of its sorption properties and allows its re-use.

\section{References}

1. B.N. Kuznetsov, Sorov Educational Journal, 12, 29 (1999)

2. V.D. Lukon, I.S. Antsipovich, Adsorbent regeneration (Chemistry, Leningrad, 1983)

3. G.V. Minkhaidarova, Ecological aspects of recycling solid carbon residue of waste tire pyrolysis (KSTR, Kazan, 2004)

4. V.M. Mukhin, A.V. Tarasov, B.N. Klushin, Activated carbons of Russia (Metallurgy, Moscow, 2000)

5. S. Murugan, M.C. Ramaswamy, G. Nagarajan, Waste Management, 28:12, 2743 (2008)

6. S. Murugan, M.C. Ramaswamy, G. Nagarajan, Fuel, 87, 2111 (2008)

7. O.Yu. Pichakhchi, Studying the possibility of using solid product of car tire pyrolysis in the process of sorption (IKST, Bombay, 2000)

8. E.P. Pozdnyakova, M.V. Statilko, Environment and industry, 1, 57 (2007)

9. M.B. Alyokhina, Industrial adsorbents: study guide (D.I. Mendeleev RCTU, Moscow, 2013)

10. V.G. Nikolsky, L.V. Vnukova, S.A. Wolfson, T.V. Dudareva, I.A. Krasotkina, Recoverable resources, 3, 99 (2008) 